\title{
Intrinsic vasomotricity and adrenergic effects in a model of isolated rabbit eye
}

\author{
Esmeralda Delgado, ${ }^{1}$ Carlos Marques-Neves, ${ }^{2}$ Isabel Rocha, ${ }^{2}$ \\ José Sales-Luís ${ }^{1}$ and Luis Silva-Carvalho ${ }^{2}$ \\ ${ }^{1}$ Clinical Department, Centre for Interdisciplinary Investigation into Animal Health, \\ Faculty of Veterinary Medicine, Technical University of Lisbon, Lisbon, Portugal \\ ${ }^{2}$ Institute of Molecular Medicine, Institute of Physiology, Faculty of Medicine, \\ University of Lisbon, Lisbon, Portugal
}

\begin{abstract}
.
Purpose: We aimed to investigate the responsiveness of the ocular arteries to adrenergic drugs in a model of perfused isolated rabbit eye.

Methods: Rabbit external ophthalmic arteries $(n=15)$ in a head-mounted preparation were cannulated and the retinal and uveal vasculature perfused at a constant flow with warmed tyrode. The three-way polypropylene catheter was further connected to a pressure transducer and intraluminal pressure was taken as a measure of vascular resistance. Effects of intra-arterial injections of phenylephrine (group $\mathrm{A}, n=5$ ), prazosin (group $\mathrm{B}, n=5$ ) and phentolamine (group $C, n=5$ ) on the recorded pressure were obtained. Student's paired- $t$ test and one-way analysis of variance were used for statistical analysis (p $<0.05)$.

Results: Intrinsic vasomotricity was observed in all preparations prior to any drug administration. Phenylephrine produced an increase in total vascular resistance. Intrinsic vasomotricity became more evident, showing a lower frequency but higher amplitude of oscillations. Evoked vasomotor responses with phenylephrine $(250 \mu \mathrm{g} / \mathrm{ml})$ were inhibited by intra-arterial administration of the selective $\alpha_{1}$-adrenergic antagonist, prazosin $(0.5 \mathrm{mg} / \mathrm{ml})$, as well as the non-selective $\alpha$-adrenergic antagonist phentolamine $(6 \mathrm{mg} / \mathrm{ml})$.

Conclusions: Rabbit external ophthalmic arteries showed spontaneous contractions under constant perfusion. Phenylephrine elicited a vasoconstrictor response that was inhibited by adrenergic antagonists. In addition, the intrinsic vasomotricity was enhanced by phenylephrine and blocked by adrenergic antagonists. These results show that under in vitro perfusion the territory presents similar responses to adrenergic drugs to those observed in in vivo models and also provides evidence of myogenic autoregulatory properties in the rabbit ophthalmic artery and/or choroid.
\end{abstract}

Key words: adrenergic drugs - isolated perfused rabbit eye - spontaneous vasomotion

Acta Ophthalmol.

(c) 2008 The Authors

Journal compilation (c) 2008 Acta Ophthalmol

doi: $10.1111 / j .1755-3768.2008 .01285 . x$

\section{Introduction}

It is well known that the choroidal circulation exerts a vital role in the metabolic support of the retina and its abnormalities. The choroidal circulation evokes different pathological conditions by either hyperperfusion or hypoperfusion of the retina, such as exudative retinal detachment or retinal ischaemia, respectively.

Dysfunction in ocular circulation is related to a wide range of disease processes that involve changes in the eye vascular profile (Roff et al. 1999), such as glaucoma, age-related macular degeneration (AMD) and diabetes. In diabetes, metabolic factors other than blood glucose are suspected to be involved in the impairment of retinal autoregulation (Jeppesen et al. 2007). Despite the different studies and methodologies used to understand choroidal circulation, several aspects of its physiology are not yet well understood, mainly because the choroid is inaccessible to direct visualization and to the interference, in humans and other animal species, of retinal circulation. As there is putative or no innervation (Foulds 1990) in the retinal vasculature as well as in the vascular system feeding the optic nerve head, the retinal circulation is controlled by autoregulatory mechanisms (Delaey \& Van der Voorde 
2000a) whereby endothelial cells play an important role in regulating vascular tone by secreting constricting and relaxing factors (Hardy et al. 2001; Okuno et al. 2002). However, controversy still exists on the extrinsic control mechanisms of choroidal circulation. In fact, choroidal blood flow is autoregulated (Kiel 1994, 2000; Kiel \& van Heuven 1995; Riva et al. 1997; Hardy et al. 2000), but is also controlled by choroidal perivascular autonomic innervation, which depends on the sympathetic system, originating from the superior cervical ganglion, parasympathetic system originating from the ciliary ganglion, and the sensory system (from the trigeminal ganglion) (Bill \& Sperber 1990; Kiel 1999; Delaey \& Van der Voorde 2000a). Parasympathetic nerve stimulation produces nitric oxide-mediated vasodilation, which appears to be selective to vessels in the anterior choroid (Mann et al. 1995; Steinle et al. 2000) and sympathetic nerves elicit marked vasoconstriction throughout the choroidal vessels via $\alpha$-nor-adrenergic mechanisms (Steinle et al. 2000). Therefore, autonomic nerves exert short-term regulatory effects on choroidal blood flow by changing vascular smooth muscle tone.

In an in vivo model of ocular circulation, interferences of stimuli originating outside the eye can occur, elicited by changes in the autonomic balance and peripheral circulation.

The purpose of this work was to develop an experimental model of isolated rabbit eye in order to abolish the neural control of ocular blood flow. The isolated perfused eye technique was pioneered by Gouras \& Hoff (1970) and further refined by Niemeyer (2001). In vitro functional studies of ophthalmic circulation involving either the perfusion of the whole eye or the study of isolated arterial segments - ophthalmic, ciliary, choroidal or retinal ( $\mathrm{Yu}$ et al. 2003) - allow for assessment of the vasoactive properties of the ocular vasculature without necessitating undesirable external interferences within the preparation.

This study aimed to develop an in situ isolated eye preparation that could be used to understand pathophysiological changes in the dynamics of the ocular circulation, particularly with respect to its local autoregulatory mechanisms, independently of neural control. We tested this model using adrenergic drugs of known effects.

\section{Materials and Methods}

\section{Anaesthesia and general surgical procedures}

New Zealand White rabbits $(n=15)$ of both sexes (body weight: 2.0$4.2 \mathrm{~kg}$ ) were anaesthetized with sodium pentobarbitone $(40 \mathrm{mg} / \mathrm{kg}$, i.v.) supplemented as necessary $(10 \%$ $\mathrm{v} / \mathrm{v}$ of the induction solution). A tracheotomy was performed low in the neck to allow artificial ventilation with $\mathrm{O}_{2}$-enriched air using a positive pressure ventilator (Harvard Apparatus Ltd, Kent, UK). In the neck, the carotid and the jugular vein were cannulated to allow the monitoring of arterial blood pressure and the administration of warm saline and drugs, respectively. The electrocardiogram (ECG) was recorded by placing intradermic electrodes in three of the four limbs. Body temperature was monitored and kept constant $\left(38-39^{\circ} \mathrm{C}\right)$ using a heating blanket (Harvard Apparatus Ltd), $1000 \mathrm{IU} / \mathrm{kg}$ heparin was administered to prevent clotting, and a waiting time of 30 mins was observed. The animals were then killed with an overdose of anaesthetic and their heads flushed via the carotid artery with $200 \mathrm{ml}$ warm tyrode solution. Immediately afterwards, the head was sectioned at cervical level, placed in a Petri dish lined with gauze swabs and immersed in freshly prepared tyrode. The head was held in position to expose the ophthalmic artery and continuously perfused with warm tyrode solution enriched with $\mathrm{O}_{2}$ through the catheter placed in the carotid artery. The medulla and pons were destroyed.

All experimental procedures conformed to the tenets of the Helsinki Declaration.

\section{Model development}

To access the ophthalmic artery, the masseter, part of the mandibular bone and the zygomatic arch were removed. After that the external ophthalmic artery was exposed, incised and a polypropylene tube with an outside diameter of $0.6 \mathrm{~mm}$ was placed in the vessel. A dissecting microscope facilitated the procedure. The catheter was further secured with sutures of 7-0 silk, and the remaining collateral vessels were ligated. The external ophthalmic artery was perfused with $\mathrm{O}_{2}$-enriched warmed tyrode delivered to the catheter by continuous i.v. infusion apparatus (series 81706; Semat Technical Ltd, London, UK) with a flow rate of $135 \mu \mathrm{l} / \mathrm{min}$. The three-way polypropylene catheter was further connected to a pressure transducer (Neurolog; Digitimer Ltd, Hertfordshire, UK) and the perfusion pressure at the external ophthalmic artery was measured. To avoid dryness and further muscle contractions the head was maintained immersed in a glass chamber containing warm $\mathrm{O}_{2}$-enriched tyrode at a constant temperature of $38^{\circ} \mathrm{C}$ and controlled $\mathrm{pH}$ (range 6.9-7.4). The bath solution was replaced during the experiment to avoid agonist build-up. Considerable care and effort was spent on a series of preliminary experiments aimed at achieving a perfused eye in the optimal physiological condition, in which we investigated choice of perfusate, flow rate, perfusion pressure and volume of agonist.

\section{Model testing}

Once perfusion commenced, an equilibration period was allowed, and no agonist delivery was attempted until the baseline perfusion pressure was stable, showing a consistent medium perfusion pressure value. After stabilization of the preparation, a vehicle control injection of $0.1 \mathrm{ml}$ tyrode was given through the catheter placed in the ophthalmic artery to view the injection artefact and the null response. Three types of experimental procedures involving the injection of drugs affecting the sympathetic nervous system were performed in different animal heads. In order to evaluate the specificity of the response to each drug, a period of time (approximately 15 mins) was allowed to elapse between each injection before the effect of a new drug was assessed. This period allowed us to establish a consistent baseline medium perfusion pressure value, allowing for a slight variation that could reflect receptor saturation. At the end of each experiment, a calibration curve was performed and methylene blue dye was injected through the ophthalmic artery to confirm eye perfusion by blue staining. 
Injection of an $\alpha$-adrenergic agent: phenylephrine

In five experiments, $0.1 \mathrm{ml}$ phenylephrine was injected through the catheter inserted in the ophthalmic artery, in three different concentrations of $25 \mu \mathrm{g} / \mathrm{ml}, 250 \mu \mathrm{g} / \mathrm{ml}$ and $2500 \mu \mathrm{g} / \mathrm{ml}$, respectively, with intervals of approximately 15 mins between injections. Changes in ophthalmic artery perfusion pressure were recorded after each injection.

\section{Injection of an $\alpha_{1}$ antagonist: prazosin} In another five experiments, we administered separate injections via the ophthalmic artery catheter of phenylephrine $(0.1 \mathrm{ml} ; 250 \mu \mathrm{g} / \mathrm{ml})$, prazosin $(0.1 \mathrm{ml} ; 0.5 \mathrm{mg} / \mathrm{ml})$, and a mixture of phenylephrine $(0.1 \mathrm{ml}$; $250 \mu \mathrm{g} / \mathrm{ml})$ and prazosin $(0.1 \mathrm{ml}$; $0.5 \mathrm{mg} / \mathrm{ml}$ ), with intervals of approximately 15 mins between injections. After each injection of drugs, changes in ophthalmic artery pressure were monitored.

\section{Injection of an $\alpha$-antagonist: phentol-} amine

In a separate set of five experiments we delivered separate injections via the ophthalmic artery catheter of phenylephrine $(0.1 \mathrm{ml} ; 250 \mu \mathrm{g} / \mathrm{ml})$, phentolamine $(0.1 \mathrm{ml} ; 6 \mathrm{mg} / \mathrm{ml})$, and a mixture of phenylephrine $(0.1 \mathrm{ml}$; $250 \mu \mathrm{g} / \mathrm{ml})$ and phentolamine $(0.1 \mathrm{ml}$; $6 \mathrm{mg} / \mathrm{ml})$, at intervals of approximately 15 mins. Changes in ophthalmic artery pressure were assessed after each injection.

\section{Drugs}

Tyrode solution comprises $\mathrm{NaCl}$ (137 mM), $\mathrm{KCl} \quad(2.7 \mathrm{mM}), \quad \mathrm{CaCl}_{2}$ (1.8 mM), $\mathrm{MgCl}_{2}(0.49 \mathrm{mM}), \mathrm{NaH}_{2} \mathrm{PO}_{4}$ (0.36 mM), $\mathrm{NaHCO}_{3}(11.9 \mathrm{mM})$, glucose $(5.6 \mathrm{mM})$ and distilled water (1000 mL).

The following drugs were used: phenylephrine, prazosin and phentolamine (Sigma Aldrich Chemie Gmbh, Steinheim, Germany). All drugs were dissolved in distilled water and freshly prepared.

\section{Data analysis}

All data were displayed online and recorded on videotape with a speed of acquisition of $100 \mathrm{~Hz}$. Arterial blood pressure and ECG were monitored using the PowerLab System (Instat, GraphPad, San Diego, CA, USA) until the animal was killed. Ophthalmic artery perfusion pressure was recorded and analysed offline using the PowerLab System. Student's paired- $t$ test and ANOva (one-way analysis of variance) were used for statistical analysis; differences were considered significant when $\mathrm{p}<0.05$. The results on the frequency of oscillations were obtained by simple counting over a given period. Data are expressed as mean \pm standard error of the mean (SEM).

\section{Results}

The period between the death of the animal and the beginning of the experiment corresponded to $41 \pm$ 1.14 mins in group $\mathrm{A}, 42.6 \pm 1.59$ mins in group $\mathrm{B}$ and $40 \pm 0.71 \mathrm{mins}$ in group $\mathrm{C}(n=15, \mathrm{p}=0.8819$, ANOVA). Equilibration periods were $16 \pm 0.71$ mins in group A, $15.2 \pm$ 0.58 mins in group B and $15.6 \pm$ $0.51 \mathrm{mins}$ in group $\mathrm{C}(n=15$, $\mathrm{p}=0.6562$, ANOvA). The total time taken to conduct experiments from the death of the animal to the end of the experiment was $105.8 \pm 1.24$ mins in group A, $107.6 \pm 1.33$ mins in group $\mathrm{B}$ and $110.4 \pm 1.40 \mathrm{mins}$ in group $\mathrm{C}(n=15, \mathrm{p}=0.0841$, ANOVA test). As p-values were $>0.05$, differences were considered not significant (i.e. the difference between means were not significantly greater than those expected by chance).

\section{Basal myogenic responses}

Before any drug administration, spontaneous myogenic responses were observed in the 15 rabbit models. This spontaneous vasomotion showed oscillations of a medium frequency of $3.6 \pm 0.66$ oscillations $/ \mathrm{min}$ and a medium amplitude value of $1.6 \pm 0.18 \mathrm{mmHg}$ (Fig. 1).

\section{Effects of adrenergic drugs on perfusion pressure}

\section{Effects of chemical stimulation with phenylephrine}

The arteries constricted in response to intra-arterial deliveries of increasing concentrations of phenylephrine (25 $\mu \mathrm{g} / \mathrm{ml}, 250 \mu \mathrm{g} / \mathrm{ml}, 2500 \mu \mathrm{g} / \mathrm{ml})$. Injection of $25 \mu \mathrm{g} / \mathrm{ml}$ phenylephrine evoked a change which resulted in an increase of $40 \%$ in perfusion pressure value $(n=5, \mathrm{p}=0.0015)$; administration of $250 \mu \mathrm{g} / \mathrm{ml}$ phenylephrine resulted in an increase of $57 \%$ $(n=5, \mathrm{p}=0.0011)$, and administration of $2500 \mu \mathrm{g} / \mathrm{ml}$ phenylephrine resulted in an increase of $66 \%$ $(n=5, \mathrm{p}=0.0021)$ (Fig. 2).

Statistical analysis with ANOva of the variation between the basal values before the three injections of phenylephrine showed that the variance was not significant $(\mathrm{p}=0.9205)$.

\section{Effects of chemical stimulation with $\alpha_{1}$-antagonist: prazosin}

Phenylephrine alone induced an increase in registered pressure of $74 \%$ $(n=5, \mathrm{p}=0.0019)$. Administration of prazosin elicited a decrease in ophthalmic pressure of $33 \% \quad(n=5$, $p=0.0040)$. Injection of a mixture of phenylephrine and prazosin elicited no difference between mean values, which resulted in no significant increase or decrease in perfusion pressure value $(n=5)$ (Fig. 3).

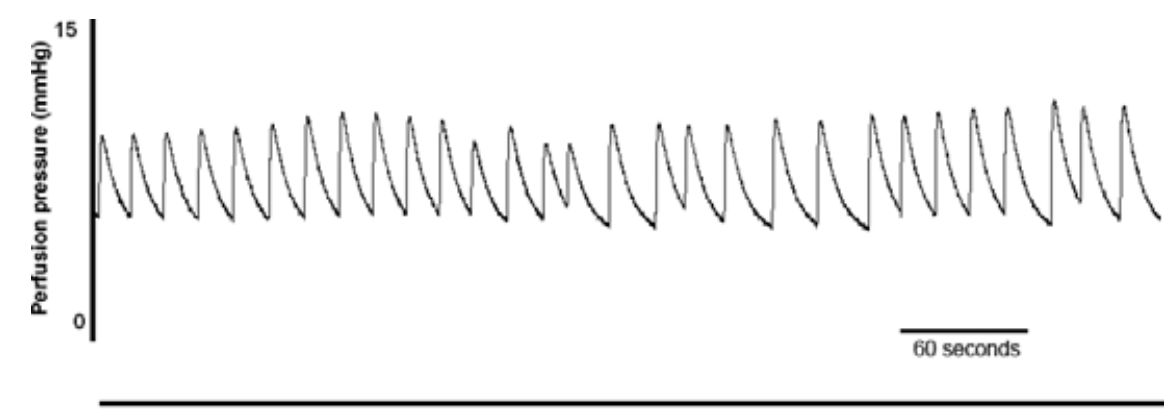

Spontaneous myogenic response

Fig. 1. Example of basal periodic oscillations in vascular tone observed without any drug administration. Perfusion pressure was recorded at the rabbit external ophthalmic artery $(\mathrm{mmHg})$. 


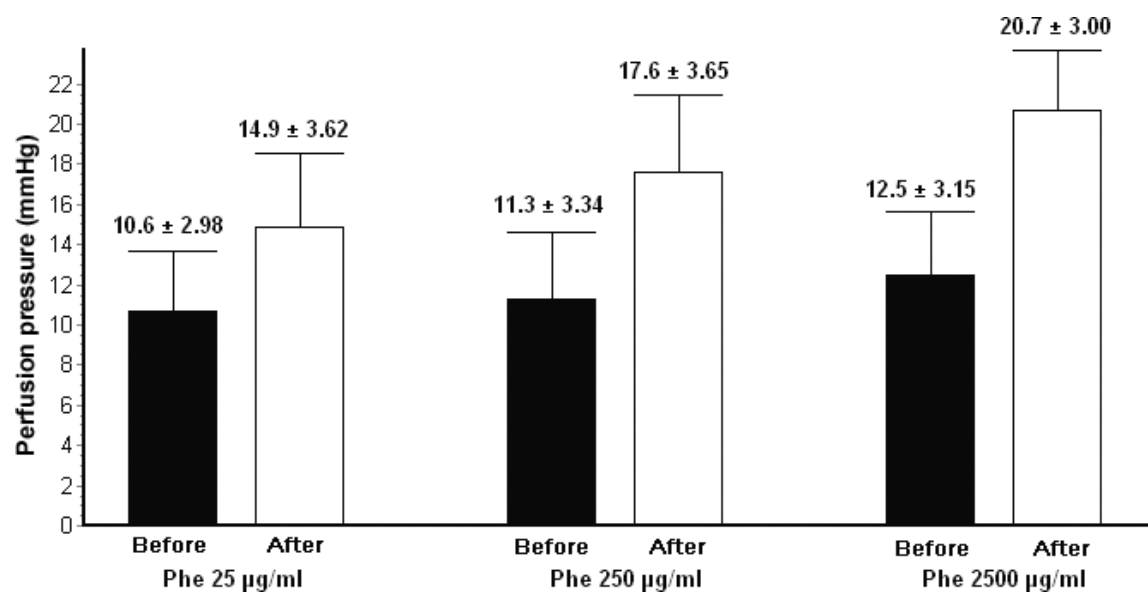

Fig. 2. Changes in perfusion pressure through the external ophthalmic artery after injection of three different doses of phenylephrine: $25 \mu \mathrm{g} / \mathrm{ml}, 250 \mu \mathrm{g} / \mathrm{ml}$ and $2500 \mu \mathrm{g} / \mathrm{ml}$. Data are expressed as mean \pm standard error of the mean. Black bars show control values; white bars show response values $(\mathrm{p}<0.05)$.

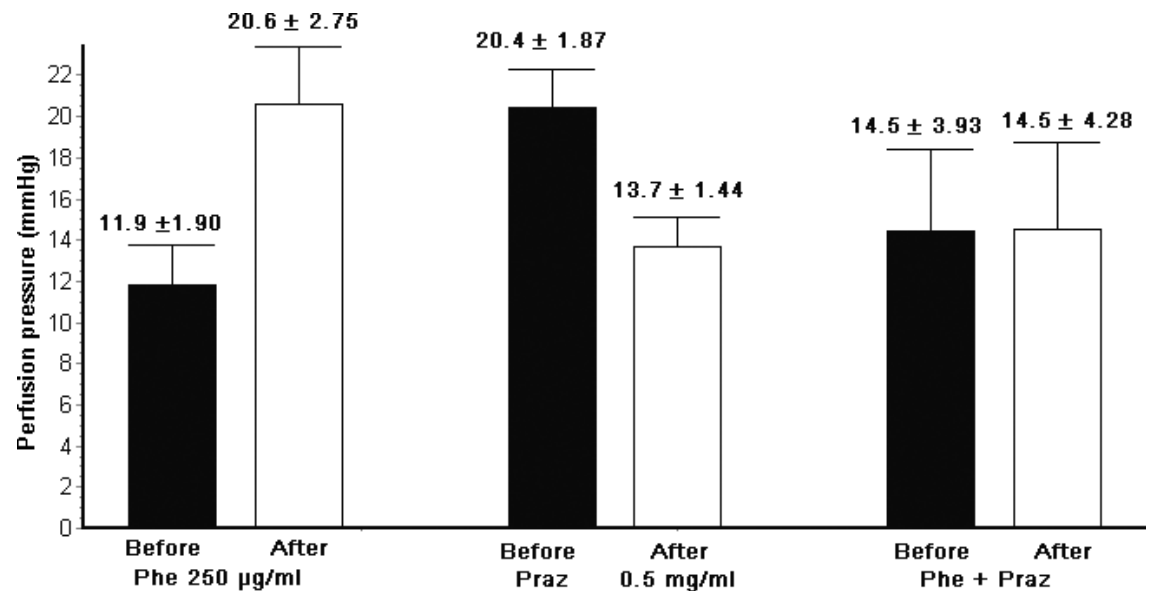

Fig. 3. Changes in perfusion pressure through the external ophthalmic artery after injection of phenylephrine (Phe) $250 \mu \mathrm{g} / \mathrm{ml}$, prazosin (Praz) $0.5 \mathrm{mg} / \mathrm{ml}$ and phenylephrine $250 \mu \mathrm{g} / \mathrm{ml}$ plus prazosin $0.5 \mathrm{mg} / \mathrm{ml}$. Data are expressed as mean \pm standard error of the mean. Black bars show control values; white bars show response values $(\mathrm{p}<0.05)$.

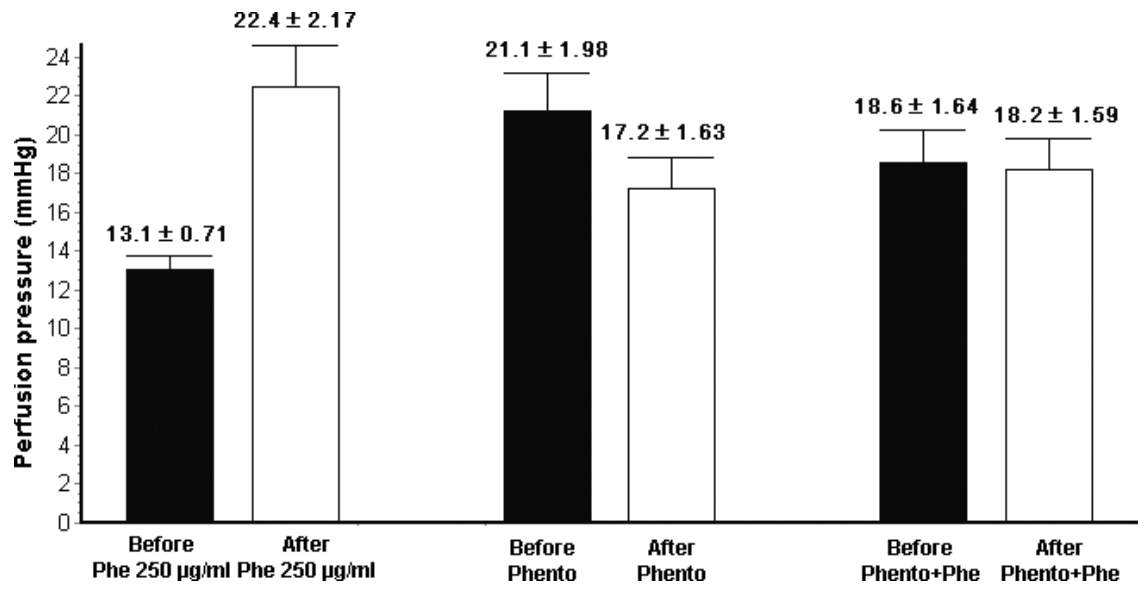

Fig. 4. Changes in perfusion pressure of external ophthalmic artery after the injection of phenylephrine (Phe) $250 \mu \mathrm{g} / \mathrm{ml}$, phentolamine (Phento) $6 \mathrm{mg} / \mathrm{ml}$ and phenylephrine $250 \mu \mathrm{g} / \mathrm{ml}$ plus phentolamine $6 \mathrm{mg} / \mathrm{ml}$. Data are expressed as mean \pm standard error of the mean. Black bars show control values; white bars show response values $(\mathrm{p}<0.05)$.
Effects of chemical stimulation with $\alpha$-antagonist: phentolamine

Injection of phenylephrine evoked an increase in perfusion pressure of $42 \%$ $(n=5, \mathrm{p}=0.0089)$. Administration of phentolamine resulted in a decrease in pressure of $19 \% \quad(n=5$, $\mathrm{p}=0.0053$ ), and injection of a mixture of phenylephrine and phentolamine resulted in a slight decrease of $2 \%(n=5, \mathrm{p}=0.0487)$ (Fig. 4).

\section{Effects of adrenergic drugs on myogenic} responses

\section{Effects of chemical stimulation with} phenylephrine

In terms of myogenic response, the initial injection of phenylephrine in all 15 rabbit models resulted in a decrease of $61 \%$ in the frequency of oscillations $(n=15, \quad \mathrm{p}=0.0004)$. However, the initial injection of phenylephrine elicited an increase of 58\% in the amplitude of oscillations $(n=15, \mathrm{p}=0.0001)$ (Figs. 5 and 6).

\section{Effects of chemical stimulation with} $\alpha_{1}$-antagonist: prazosin

In terms of myogenic activity, injection of prazosin evoked a decrease of $69 \%$ in the frequency of oscillations $(n=5, \mathrm{p}=0.0161)$ and a decrease of $75 \%$ in the amplitude of oscillations $(n=5, \mathrm{p}=0.0061)$ (Figs. 5 and 6).

\section{Effects of chemical stimulation with} $\alpha$-antagonist: phentolamine

In terms of myogenic responses, phentolamine injection evoked a decrease of $53 \%$ in the frequency of oscillations $(n=5, \quad \mathrm{p}=0.0014)$ and a decrease of $77 \%$ in the amplitude of oscillations $\quad(n=5, \quad \mathrm{p}=0.0003)$ (Figs 5 and 6). Trace examples are shown (Figs. 7-9).

\section{Discussion}

The purpose of this study was to increase our understanding of the control of ocular circulation. We developed an experimental model of an isolated rabbit eye in order to avoid the neural control of ocular blood flow and to assess local autoregulatory mechanisms.

To test the reliability of our model, we used adrenergic drugs with known vasoconstricting and vasodilating effects. Our purpose was not to define a dose-dependent relationship or to 




Fig. 5. Changes in frequency of the oscillations of the myogenic response through the external ophthalmic artery after injection of phenylephrine (Phe) $250 \mu \mathrm{g} / \mathrm{ml}(n=15)$, prazosin (Praz) $0.5 \mathrm{mg} / \mathrm{ml}(n=5)$, and phentolamine (Phento) $6 \mathrm{mg} / \mathrm{ml}(n=5)$. Data are expressed as mean \pm standard error of the mean. Black bars show the medium of the frequency values before drug injections; white bars show the values after drug injections $(\mathrm{p}<0.05)$.

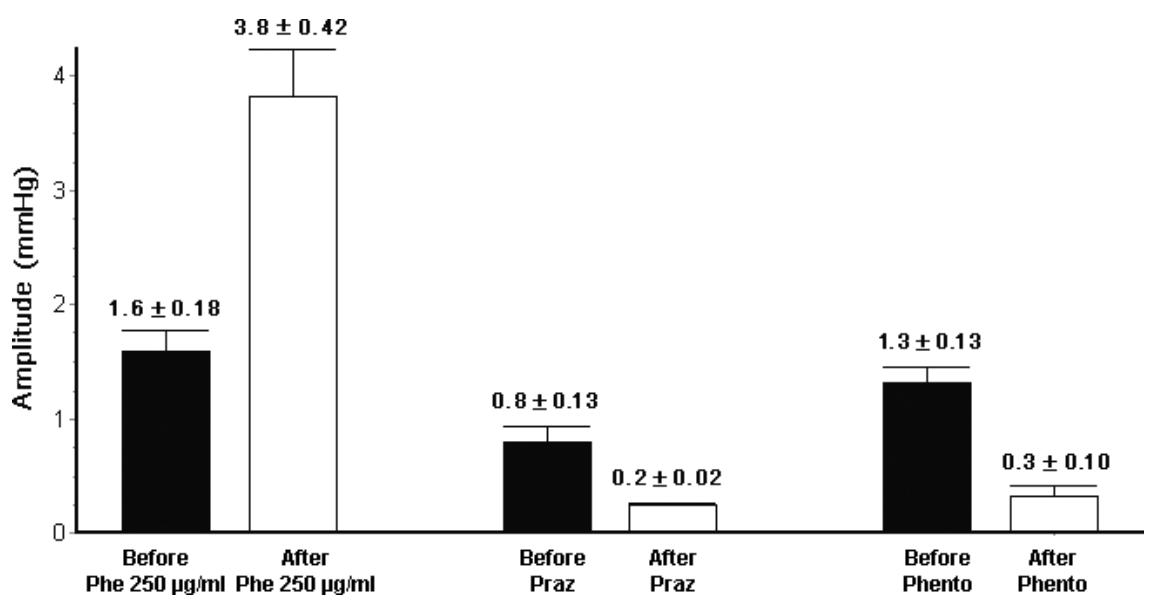

Fig. 6. Changes in amplitude of oscillations of the myogenic response through the external ophthalmic artery after injection of phenylephrine (Phe) $250 \mu \mathrm{g} / \mathrm{ml}(n=15)$, prazosin (Praz) $0.5 \mathrm{mg} / \mathrm{ml}(n=5)$ and phentolamine (Phento) $6 \mathrm{mg} / \mathrm{ml}(n=5)$. Data are expressed as mean \pm standard error of the mean. Black bars show the medium of frequency values before drug injections; white bars show the values after drug injections $(\mathrm{p}<0.05)$.



\section{Basal data inj. $\quad$ Effect observed after the drug infection}

Fig. 7. Example of changes in vascular tone observed after a phenylephrine injection. There is marked vasoconstriction as well as a decrease in frequency and increase in amplitude of oscillations. Perfusion pressure was recorded at the rabbit external ophthalmic artery (in $\mathrm{mmHg}$ ). perform a pharmacological study. In fact, for the validation process, we studied systematically, and qualitatively rather than quantitatively, the effect of a vasoactive constricting drug (phenylephrine), the effects of two catecolaminergic antagonists and, in a third stage, the combined effect of phenylephrine and each of the catecolaminergic antagonists.

Briefly, our results show that administration of phenylephrine instigated an increase in pressure in the ophthalmic artery. By contrast, after injection of the two catecolaminergic antagonists, a decrease in ophthalmic pressure was observed. The combined effect of phenylephrine with the antagonist showed that the vasoconstricting effect of phenylephrine was partially inhibited by the catecolaminergic antagonist. Administration of an $\alpha_{1}$ - versus an $\alpha$-antagonist did not elicit significant differences in the observed pressure responses, thus suggesting, together with previous studies (Van Pixteren 1985; Koss \& Gherezghiher 1993; Kiel \& Lovell 1996; Kawarai \& Koss 1998), the presence of an $\alpha_{1}$-mediated vasoconstriction mechanism in rabbit eye circulation.

One major finding of this study was the presence of spontaneous myogenic activity in the rabbit ophthalmic artery in vitro.

Vasomotion refers to periodic oscillations in vascular tone that ensure the intermittent supply of blood to adjacent microvascular units. Several studies in isolated porcine (Hoste et al. 1989; Nyborg et al. 1990; Yu et al. 1994; Hessellund et al. 2003; Jeppesen et al. 2003) or bovine (Delaey \& Van de Voorde 2000b) retinal arteries studied in a myograph suggest that there are basal oscillations in vascular tone. Another study revealed myogenic tone and reactivity of isolated rat external ophthalmic artery (Jarajapu et al. 2004).

To our knowledge, this is the first report of spontaneous vasomotion in the rabbit external ophthalmic artery and its collaterals in an isolated model of rabbit eye. Our isolated eye model maintains the arterial and venous vascular connections, which probably allows a more correct visualization of these oscillations than an isolated artery. Moreover, the low perfusion pressure present in our model probably elicits an autoregulatory 




Basal data

inj. 1 Effect observed after the drug infection
Fig. 8. Example of changes in vascular tone observed after a phentolamine ( $\alpha$-blocker) injection. There is vasodilatation as well as a decrease in frequency and amplitude of oscillations. Perfusion pressure was recorded at the rabbit external ophthalmic artery (in $\mathrm{mmHg}$ ).

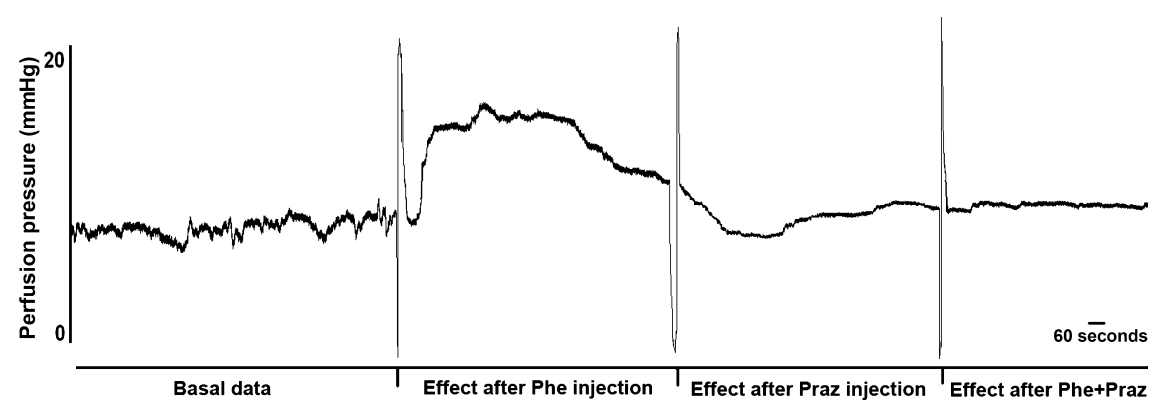

Fig. 9. Example of a trace of a whole experiment, from the prazosin group. We can see that the phenylephrine injection elicited an increase in perfusion pressure, prazosin produced a decrease and the injection of both drugs together did not cause any change in PP. Perfusion pressure was recorded at the rabbit external ophthalmic artery (in $\mathrm{mmHg}$ ).

vascular response in rabbit ocular circulation. This response probably exists to respond to hypotensive situations to prevent ischaemia of the ocular tissues or it may regulate ocular blood perfusion in cases of systemic hypertension that, fortunately, are not correlated with situations of ocular hypertension.

Elsewhere in the circulation, myogenic autoregulation performs an important homeostatic function by maintaining capillary hydrostatic pressure during fluctuations in arterial pressure. By stabilizing capillary pressure, myogenic autoregulation also minimizes arterial pressure-dependent changes in blood volume downstream from the resistance vessels. Because it takes changes in ocular volume of only microlitres to produce significant changes in intraocular pressure (IOP), it is possible that choroidal myogenic autoregulation stabilizes IOP during the normal transient variations in systemic arterial pressure associated with daily activities (Kiel 1994).
In general, in studies that decreased the perfusion pressure by increasing IOP while maintaining a constant mean arterial pressure (MAP), no autoregulation was found. By contrast, the study by Kiel \& Shepperd (1992) found autoregulation when the perfusion pressure was decreased by lowering the MAP and holding the IOP constant at $15 \mathrm{mmHg}$ and $5 \mathrm{mmHg}$ in rabbits. However, even more pronounced autoregulation was found in a later study (Kiel 1994), when perfusion pressure was varied by raising and lowering the MAP without controlling the IOP. These findings suggest that MAP may be a better stimulus to elicit choroidal autoregulation than IOP, and that the failure of previous studies to observe choroidal autoregulation might be related to their use of IOP to vary ocular perfusion pressure. Such a mechanism might be beneficial in stabilizing IOP during MAP fluctuations that are too brief for aqueous compensation to respond to (Kiel 1994).
The vasospastic syndrome corresponds to a contraction of the muscle cells of the arterial wall and is thought to be correlated with a higher prevalence of ocular ischaemic diseases (Gasser \& Flammer 1987; Gasser 1999). These patients exhibit faster pulse waves in the retinal vessels (Gugleta et al. 2006), which may correspond to a stronger intrinsic myogenic tone.

In our study, myogenic behaviour was modulated by adrenergic drugs. The observed increase in the amplitude of the oscillations of myogenic vascular tone with phenylephrine and the blunting of myogenic responsiveness with the adrenergic antagonists which lowered the frequency and amplitude of the oscillations indicate that neural sympathetic regulation superimposes on local myogenic autoregulation.

This study provides evidence that the rabbit ocular vasculature exhibits autoregulatory myogenic tone in response to a low perfusion pressure. Our results were obtained under constant flow conditions, which are expected to modulate the arterial diameter through endothelial mechanisms (Meyer et al. 1993). Thus, we believe the intrinsic vasomotricity observed depends on the influences of both myogenic tone and endothelium regulation.

The experimental design cannot determine the arterial segment responsible for the myogenic tone. Clinical studies use ophthalmic artery haemodynamics as a measure of the overall function of ophthalmic circulation (Krejcy et al. 1997; Yu et al. 2003; Ito et al. 2006). However, because of its merangiotic type of retinal circulation, the rabbit is commonly used as a model for choroidal studies; therefore, we believe that although the ophthalmic artery might be involved, the most significant change in resistance occurs in the smaller vessels in the choroid.

Our results confirm our experimental model of the isolated perfused eye as a reliable model with which to study local regulatory mechanisms of choroidal circulation. Its reliability has been proved by the vascular responses elicited by the administration of drugs into the ophthalmic artery in the absence of extrinsic factors such as nervous control or 
systemic blood pressure. We believe that this isolated perfused rabbit eye represents a valuable technique for investigating the vascular reactivity of eye circulation.

\section{Acknowledgements}

The results of this study were presented at the Congress of the European College of Veterinary Ophthalmology/ European Society of Veterinary Ophthalmology, Oporto, Portugal, 15-19 June 2005 (Delgado et al. 2005a,b). This work was supported by the Centre for Interdisciplinary Investigation into Animal Health (Centro de Investigação Interdisciplinar em Sanidade Animal).

\section{References}

Bill A \& Sperber G (1990): Control of retinal and choroidal blood flow. Eye 4: 319-325.

Delaey C \& Van der Voorde J (2000a): Regulatory mechanisms in the retinal and choroidal circulation. Ophthalmic Res 32: 249-256.

Delaey C \& Van de Voorde J (2000b): Pressure-induced myogenic responses in isolated bovine retinal arteries. Invest Ophthalmol Vis Sci 41: 1871-1875.

Delgado E, Marques-Neves C, Rocha I, Sales-Luis J \& Silva-Carvalho L (2005a): Adrenergic reactivity and intrinsic vasomotricity in a perfused model of isolated rabbit eye. Vet Ophthalmol 8: 431.

Delgado E, Marques-Neves C, Rocha I, Sales-Luis J \& Silva-Carvalho L (2005b): Adrenergic reactivity and myogenic tone in a perfused model of isolated rabbit eye. Paper presented at the Congress of the European College of Veterinary Ophthalmology/European Society of Veterinary Ophthalmology, Oporto, Portugal, 15-19 June 2005.

Foulds WS (1990): The choroidal circulation and retinal metabolism - an overview. Eye 4: 243-248.

Gasser P (1999): Why study vascular factors in glaucoma? Int Ophthalmol 22: 221-225.

Gasser P \& Flammer J (1987): Influence of vasospasm on visual function. Doc Ophthalmol 66: 3-18.

Gouras P \& Hoff M (1970): Retinal function in an isolated, perfused mammalian eye. Invest Ophthalmol Vis Sci 9: 388-399.

Gugleta K, Kochkorov A, Katamay R, Zawinka C, Flammer J \& Orgül S (2006): On pulse-wave propagation in the ocular circulation. Invest Ophthalmol Vis Sci 47: 4019-4025.

Hardy P, Dumont I, Bhattacharya M, Hou $\mathrm{X}$, Lachapelle $\mathrm{P}$, Varma D \& Chemtob $\mathrm{S}$ (2000): Oxidants, nitric oxide and prostanoids in the developing ocular vasculature: a basis for ischaemic retinopathy. Cardiovasc Res 47: 489-509.

Hardy P, Lamireau D, Hou X, Dumont I, Abran D, Nuyt A, Varma D \& Chemtob S (2001): Major role for neuronal NO synthetase in curtailing choroidal blood flow autoregulation in newborn pig. J Appl Physiol 1: 1655-1662.

Hessellund A, Jeppesen P, Aalkjaer C \& Bek T (2003): Characterization of vasomotion in porcine retinal arterioles. Acta Ophthalmol Scand 81: 278-282.

Hoste A, Boels P, Brutsaert D \& De Laey J (1989): Effect of $\alpha_{1}$ and $\beta$ agonists on contraction of bovine retinal resistance arteries in vitro. Invest Ophthalmol Vis Sci 30: 44 50.

Ito I, Jarajapu Y, Guberski D, Grant M \& Knot H (2006): Myogenic tone and reactivity of rat ophthalmic artery in acute exposure to high glucose and in a type II diabetic model. Invest Ophthalmol Vis Sci 47: 683-692.

Jarajapu Y, Grant M \& Knot H (2004): Myogenic tone and reactivity of the rat ophthalmic artery. Invest Ophthalmol Vis Sci 45: 253-259.

Jeppesen P, Aalkjaer C \& Bek T (2003): Myogenic response in isolated porcine retinal arterioles. Curr Eye Res 27: 217-222.

Jeppesen P, Knudsen ST, Poulsen PL, Mogesen CE, Schmitz O \& Bek T (2007): Response of retinal arteriole diameter to increased blood pressure during acute hyperglycaemia. Acta Ophthalmol Scand 85: 280-286.

Kawarai M \& Koss M (1998): Sympathetic vasoconstrition in the rat anterior choroids is mediated by $\alpha_{1}$-adrenoceptors. Eur $\mathrm{J}$ Pharmacol 363: 35-40.

Kiel J (1994): Choroidal myogenic autoregulation and intraocular pressure. Exp Eye Res 58: 529-543.

Kiel J (1999): Modulation of choroidal autoregulation in the rabbit. Exp Eye Res 69: 413-429.

Kiel J (2000): Endothelin modulation of choroidal blood flow in the rabbit. Exp Eye Res 71: 543-550.

Kiel J \& Lovell M (1996): Adrenergic modulation of choroidal blood flow in the rabbit. Invest Ophthalmol Vis Sci 37: 673-679.

Kiel J \& Shepperd A (1992): Autoregulation of choroidal blood flow in the rabbit. Invest Ophthalmol Vis Sci 33: 2399-2410.

Kiel J \& van Heuven J (1995): Ocular perfusion pressure and choroidal blood flow in the rabbit. Invest Ophthalmol Vis Sci 36: 579-585.

Koss M \& Gherezghiher T (1993): Adrenoceptor subtypes involved in neurally evoked sympathetic vasoconstriction in the anterior choroid of cats. Exp Eye Res 57: 441-447.

Krejcy K, Wolzt M, Kreuzer C, Breiteneder H, Schutz W, Eichler HG \& Schmetterer L (1997): Characterization of angiotensin-II effects on cerebral and ocular circulation by non-invasive methods. Br J Clin Pharmacol 43: 501-508.
Mann R, Riva C, Stone R, Barnes G \& Cranstoun S (1995): Nitric oxide and choroidal blood flow regulation. Invest Ophthalmol Vis Sci 36: 925-930.

Meyer P, Flammer J \& Luscher T (1993): Endothelium-dependent regulation of the ophthalmic microcirculation in the perfused porcine eye: role of nitric oxide and endothelins. Invest Ophthalmol Vis Sci 34 3614-3621.

Niemeyer G (2001): Retinal research using the perfused mammalian eye. Prog Retina Eye Res 20: 289-318.

Nyborg N, Korsgaard N \& Nielsen P (1990): Active wall tension-length curve and morphology of isolated bovine retinal small arteries: important feature for pharmacodynamic studies. Invest Ophthalmol Vis $\mathrm{Sci}$ 51: $217-224$.

Okuno T, Hidehiro O, Sugiyama T, Yang Y \& Ikeda $\mathrm{T}$ (2002): Evidence that nitric oxide is involved in autoregulation in optic nerve head of rabbits. Invest Ophthalmol Vis Sci 43: 784-789.

Riva C, Titze P, Hero M \& Petrig B (1997): Effect of acute decreases of perfusion pressure on choroidal blood flow in humans. Invest Ophthalmol Vis Sci 38: 1752-1760.

Roff E, Harris A, Chung H, Hosking S, Morrison A, Halter P \& Kagemannn L (1999): Comprehensive assessment of retinal, choroidal and retrobulbar haemodynamics during blood gas perturbation. Graefes Arch Clin Exp Ophthalmol 237: 984-990.

Steinle J, Krizsan-Agbas D \& Smith P (2000): Regional regulation of choroidal blood flow by autonomic innervation in the rat. Am J Physiol Regul Integr Comp Physiol 279: 202-209.

Van Pixteren P (1985): Hypotensive effects after topical and intra-arterial administration of $\alpha$-adrenergic agonists in isolated perfused rabbit eyes. Ophthalmic Res 17: 349-353.

Yu D, Alder V, Cringle S, Su E \& Yu P (1994): Vasoactivity of intraluminal and extraluminal agonists in perfused retinal arteries. Invest Ophthalmol Vis Sci 35: 4087-4099.

Yu D, Su E, Cringle S \& Yu P (2003): Isolated preparations of ocular vasculature and their applications in ophthalmic research. Prog Retin Eye Res 22: 135-169.

Received on December 9th, 2007.

Accepted on March 6th, 2008.

Correspondence:

Esmeralda Delgado

Departamento de Clínica

CIISA

Faculty of Veterinary Medicine

Alameda da Universidade Técnica

1300-477 Lisbon

Portugal

Tel: + 351213652893

Fax: + 351213652822

Email: esmeralda@fmv.utl.pt 